\title{
An SOA Approach to Virtual Classroom with Content Repurposing
}

\author{
http://dx.doi.org/10.3991/ijet.v9i1.3064 \\ Kong Xiangsheng \\ Xin Xiang University, Xin Xiang, China
}

\begin{abstract}
Existing M-Learnings lack security, privacy and wireless accessibility features so that they are prevented from expanding widely and usually have problems that they lack S.C.A.L.E. (Scalability, Connectivity, Adaptability, Liability, and Ease-of-use) design factors that a typical ubiquitous system must support. One of the ways lies in the evolution of learning environments into Service Governance of Service Oriented Architecture. The implementation of this architecture will allow the creation of Mobiles and external tools that can work with the resources contained in the platform, and give trainers and learners a freedom of movement that they did not have before.
\end{abstract}

Index Terms-LMS, virtual classroom, Service Governance, Learning Object Metadata

\section{INTRODUCTION}

In recent years, an explosion is occurring in the demand for distance education in China. Large numbers of highschool graduates are going on to college, and more adults are pursuing a college education. The demographics of college students also are changing, and the changes in knowledge and skills catalyze the need for ongoing professional development of the existing workforce. More and more higher education institutions use Electronic learning (E-Learning), as a tool to assist delivering educational resources including text, picture, multimedia or video what are made by computer software to students, either as a supplement to courses delivered traditionally or as an entire course offered online. E-Learning as a contender to classical face-to-face learning is broadly defined as learning through electronic devices. It is sought to further enrich this process with the ability to access all the educational resources wanted, when it is wanted, that is to say that knowledge can be available all time. This objective could be considered as the main target of learning platforms (LMS, Learning Management Systems)[1,2]. One of the most extended platforms of learning is Moodle.

Nowadays, with the development of mobile devices (especially mobile phones booming) and trends mobile applications in the areas of modern life such as communication, entertainment and education, a new form of learning environment was any setting in which students can become totally immersed in the learning process, namely, the mobile learning (M-Learning). The term M-Learning refers to the use of handheld devices such as personal digital assistants (PDAs), smart phones, Tablet PCs, e-Books, palmtops, and any other mobile microprocessor-based information technology devices that can be used in teaching and learning anytime/anywhere. Taking this into account, the next logical step in the development of E-
Learning is to apply mobile technology to current LMS, the Mobile LMS.

With the maturity of portal technology, more and more M-Learning are using Portal technology (Enterprise Information Portal) as user interfaces to aggregate class information and services and allow the users to personalize and customize their views of these classes, services and information. How to apply portal technology to mobile devices is a more challenging question.

\section{State OF THE ART AND RElAted Work}

The research field of mobile learning is a very challenging one, because there must be faced technical issues related to the continuously evolving state of the art, as well as issues that belong to the field of usability, pedagogy and learning design. To guarantee an impact on this work, all development will be based on the LMS Moodle which is a great Free/Libre and Open Source Software (FLOSS) tool that teachers can use to facilitate student collaboration in many ways that use not possible otherwise because it is a platform to save and achieve teaching material easily and a collaborative online platform for teachers and students to learn together [3].

There are several studies of this type with Moodle but most of them are in process or are not released. One initiative is the Moodle for Mobiles project (MFM). MFM takes advantage of the current low fees for mobile email. MFM which uses the push email service (like RIM's Blackberry) to access the virtual class contents implements a gateway that sends updates from the Moodle webbased virtual classroom to iMode technology enabled devices. The use of the e-mail client (Blackberry, Mobile GMail, RealMail etc.) to get the information from the virtual class has an important limitation: it is usually used in Japan. Another initiative is the Mobile Learning Engine project (MLE). MLE provides a mobile client for Java Micro Edition (JavaME) that can be plugged to LMS software. However this adaptation is always partial and specific of a particular M-Learning platform. In addition, it is developed under proprietary code and license, so the code is not available. Apart from these, there exist some applications for Moodle on the mobile but natives, that is, only for a specific mobile platform. For example for IPhone are mTouch, mPage, Moodle4IPhone or ILite. Also there exist specific implementations of Moodle for Android like MOMO, MBot or Moodbile. However, most of them are not operative or are not accessible.

\section{LEARNING RESOURCE REPURPOSING}

In order to improve the reuse of educational resources in digital format appears the concept of "learning ob- 
ject"(LO). A LO includes not only educational content, but also metadata descriptions that describe the own object and make easier its use and location in other contexts, LOs standards are used. An example of the metadata's standard is the LOM (Learning Object Metadata) XML scheme [4], which was developed by LTSC. LOM defines a wide range of metadata to classify and characterize learning resources, which include: overall description (cataloguing, annotations, and associations and relationships with other learning resources), technical data (file size, format, installation/usage descriptions), educational data (educational purpose, learning objectives, classification), and management data (intellectual property rights).The purpose of this standard is to facilitate search, evaluation, acquisition and use of LOs, both by students and instructors, or even automated software processes. However, there are no generally accepted conventions for properly describing learning objectives or the learning context, and although attempts have been made (such CLEO, and Educational Markup Languages) these only capture some of the semantics; thus more complex models are needed.

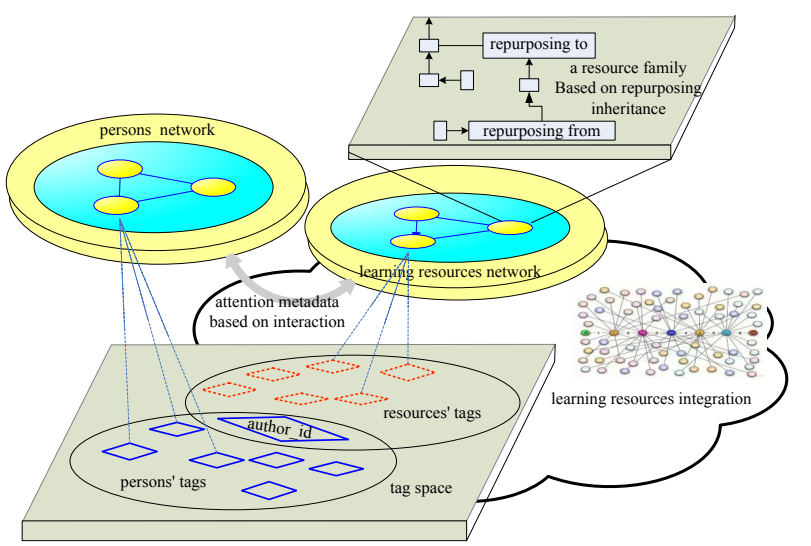

Figure 1. Learning Resource In M-Learning

We use the term "learning resource" to imply a defined package of structured, factual information that is linked with a specific educational context. Here, context is defined as a set of circumstances in which an educational resource is used or may be used. The various ways of exploiting educational resource as social objects have been implemented in the MetaMorphosis+ social network(shown in Figure 1) [5,6], which can be viewed as two distinctive and interacting networks. MetaMorphosis+ is based on three-layer architecture:

(a) Educational Web data and service layer: it consists of Web services exposing available educational resource metadata that exist in disparate Web repositories.

(b) Educational data and service integration layer: it facilitates integration of actual LOM.

(c) Educational application and presentation layer: it will be discussed in part IV.

\section{M-LEARNING ARCHITECTURE WITH SERVICE GOVERNANCE AND SOA}

The problem of delivering educational contents through the web and its integration with LMS has been widely studied. But education is not only about contents, as the last educational models make explicit (connectivism and social constructionism). In order to incorporate interoperability in learning platforms and make them flexible and scalable, it is necessary to define a new generation of learning platforms. These kinds of platforms are going to be based on service-oriented architecture (SOA). S.C.A.L.E. is the main axis that SOA based M-Learning researchers attempt to address, solve, and enhance eLearning systems. SOA is a concept in software architecture that is based on creating a set of services between business processes and applications of varying granularity. This type of solution will provide a separation between the service interface and its underlying implementation. It will no longer be important whether an application that wants to connect to a platform is implemented in a different technology from the core of the LMS. SOA provides independence in the evolution of software, which allows adding new functionalities whatever the underlying LMS version. This architecture has as its main objectives [7]: 1) Model the business logic as services; 2) Provide access to functionality without knowing the underlying technology; 3) Minimize technological dependencies between the business layer and the application layer, so being able to change both independently.

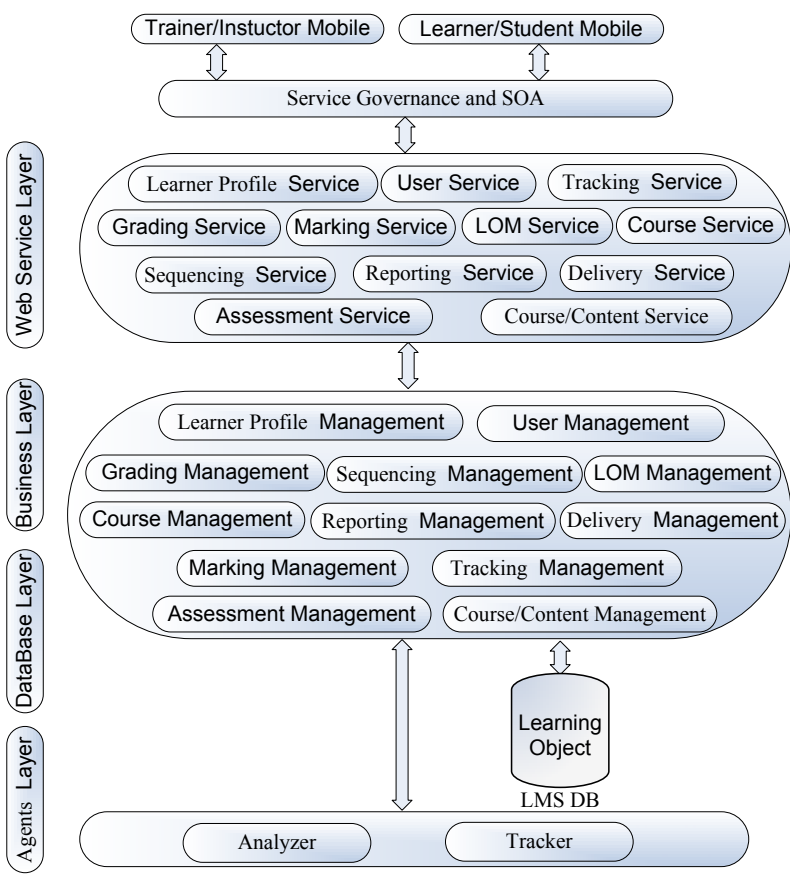

Figure 2. M-Learning Architecture with SOA

The general system architecture of M-Learning based on SOA is shown in Figure 2. The architecture system is divided into subsystem components for applying tier (layer) based and component based system design approach for its functionalities [8]. The system is mainly focused on SOA. The system components include Database Layer, Interface layer, and Service layer. 


\section{A. Database Layer}

Database layer consists of LOs, including context data, content data, learner's profile and test. First, the context data is the information about location, time, and manner that learners take part in the course via a mobile device. Secondly, the content data stores information about course materials that reflects in the content model. The learner profile represents personalized information of each learner including learner's interests, learner's knowledge level, and interval of time that learners requested. Finally, test data consists of several questions for testing student's knowledge level. Besides, test data also store the results of learner's test.

\section{B. Interface Layer}

It is the main gate of the system with users and other services providers/consumers. M-Learning has two main types of users: Instructors, and Learners. Each user type has a stand alone portal that provides different functionalities for each user. Display service is responsible for preparing dynamic output prepared to users, and calling the suitable web page to display data. Display service passes suitable set of data to appropriate pages, and acquires input from users when needed. There is no business logic embedded within this layer. Separation of interface design and implementation from business logic has proven many advantages. Other services providers/consumers like Mediator have Web services as the interface of machines that represent service providers/consumers. M-Learning and Mediator expose set of Web services required to satisfy system supported processes under SOA design pattern.

\section{Service Layer}

Service layer is the layer that holds services composing core of the M-Learning. Service layer has three sub layers: Agents layer, Business layer, Web Service, Service Governance and SOA.

\section{Agents layer}

Specific task agents are required to serve system. Software agents are always the optimum solution for track and analysis tasks. Software agents are: Analyzer, and Tracker Agents. Analyzer agent is the software agent that analyzes system's log to detect most happen reasons causing failed imports, thus provide a feed-forward dynamic M-Learning [9]. Tracker agent is the software agent that is responsible for ensuring that instructors provided feedback for courses they have imported.

\section{E. Business layer}

Business layer manages interaction details required to ensure that service operations are executed in a specific sequence. This layer provides Service Governance to the SOA framework of our system. It sets rules on the access of all services. Sequences are determined based on processes supported by system. Business within this layer is: Assessment Management, Grading Management, Marking Management, Course Management, LOM Management, Tracking Management, User Management, Sequencing Management, Reporting Management, Delivery Management, Learner Profile Management and Course/Content Management.

\section{F. Web Service}

SOA which includes Assessment Service, Grading Service, Marking Service, Course Service, LOM Service, Tracking Service, User Service, Sequencing Service, Reporting Service, Delivery Service, Learner Profile Service and Course/Content Service.

\section{G. Service Governance and SOA}

Configurability, maintainability, and reusability usually are problems to design and implement for most of systems. M-Learning systems can be developed anywhere and depending upon their locations, the system configurations can vary. It is not feasible to accommodate all necessary changes without Service Governance and SOA. Mule ESB is a lightweight Java-based messaging framework that allows you to easily connect your applications, extend the functionality of the bus and enable them to exchange data. Mule is based on ideas from Enterprise Service Bus (ESB) architectures. The strict separation of configuration and business in Mule was another reason to choose Mule for M-Learning.

Endpoints are configuration elements that are the key to wiring together all the services. By specifying endpoints in the inbound and outbound routers to tell Mule which transport to use, where to send messages, and which messages a service component should receive. The primary part of an endpoint is the address, expressed as a uniform resource indicator (URI), which indicates the transport to use, the location (a transport-specific resource), and any additional parameters. Mule Galaxy, a governance solution for Mule, is a SOA governance platform, often referred to as an SOA registry/repository. Galaxy aids in the management of SOA by providing features such as lifecycle, dependency and artifact management, service discovery and reporting, and application deployment management. Galaxy can provide a global configuration application (shown in Figure 3).

When a message is sent from an application (such as the invoice from an course entry system), Mule picks up the message, sends it to a service that processes it using some specific business logic (such as checking the LO databases), and then routes it to the correct application (such as the course fulfillment system). Mule contains many individual parts that handle the processing and routing of the message. The key part of the service is the service component. The service component executes business logic on messages, such as reading the invoice object, adding information to it from the customer database, and then forwarding it to the course fulfillment application (shown in Figure 4).

Mule Galaxy can get control over M-Learning infrastructure by providing the following features:

a) Governance: provides a centralized control point for M-Learning's policy management and compliance, ensuring that SOA adheres to M-Learning's policies.

b) Registry: automatically detects and displays dependencies among services and manages service lifecycles.

c) Repository: stores and manages artifacts (including LO \& LOM, Mule configuration files, web services frameworks, and any other artifact), providing version management and collaborative comments, and publishes the course materials in mobile. 
PAPER

AN SOA APPROACH TO VIRTUAL CLASSROOM WITH CONTENT REPURPOSING

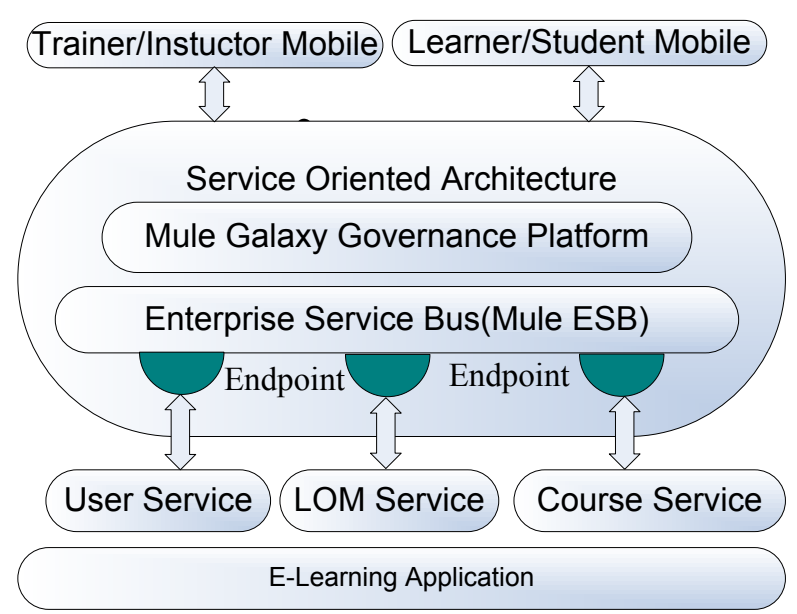

Figure 3. Mule and Galaxy in M-Learning

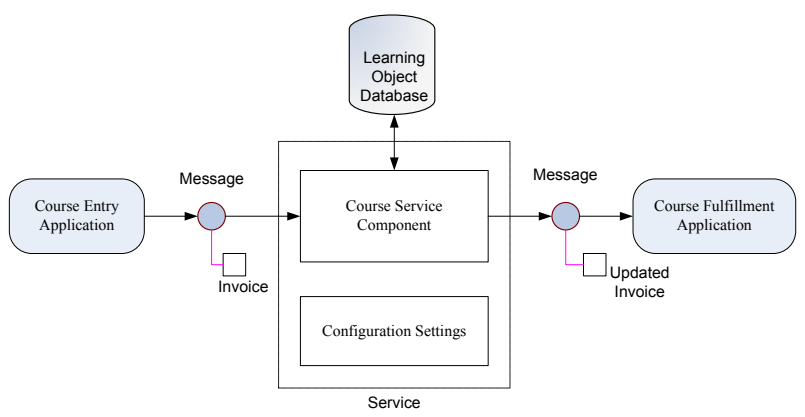

Figure 4. Mule and Galaxy in M-Learning

\section{THE ALGORITHM}

M-Learning systems can be developed anywhere and depending upon their locations, the system configurations can vary. It is not feasible to accommodate all necessary changes without Service Governance and SOA.

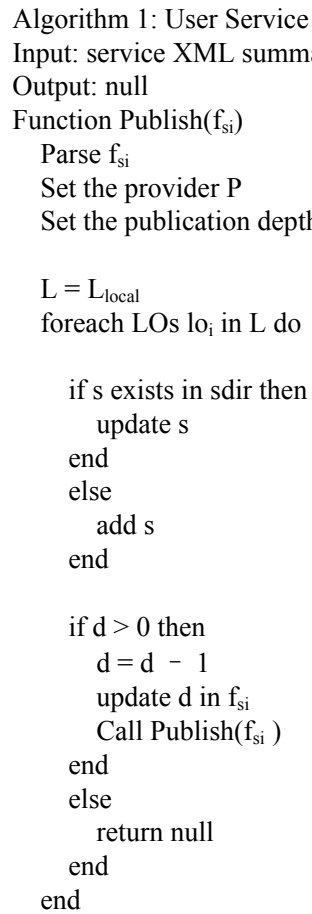

Algorithm 1 outlines the proposed publication mechanism for user services. The publication process is distrib- uted and recursive in that providers can allow LOs to propagate the publication of the service on their behalf using their own resources. The publication depth $\mathrm{d}$ indicates how far the service provider wants the advertisements to reach. The LO list L is initially set to the providers' LO list $\mathrm{L}_{\text {local }}$. A LO lo $\mathrm{l}_{\mathrm{i}}$ receives the service advertisement, reduces $\mathrm{d}$ by 1 and republishes the service to its LO list $\mathrm{LO}_{\mathrm{i}}$, according to a prospected pattern of access rights for indirect $\mathrm{LO}_{\mathrm{s}}$ These access rights are set by providers via appropriate mechanisms. The publication stops when $\mathrm{d}$ reaches " 0 ". If the service provider sets $d$ to " 0 " for a particular service $\mathrm{s}$, it means that $\mathrm{s}$ is only offered to the provider's direct LOs and the recipient of the announcement is not allowed to republish it.

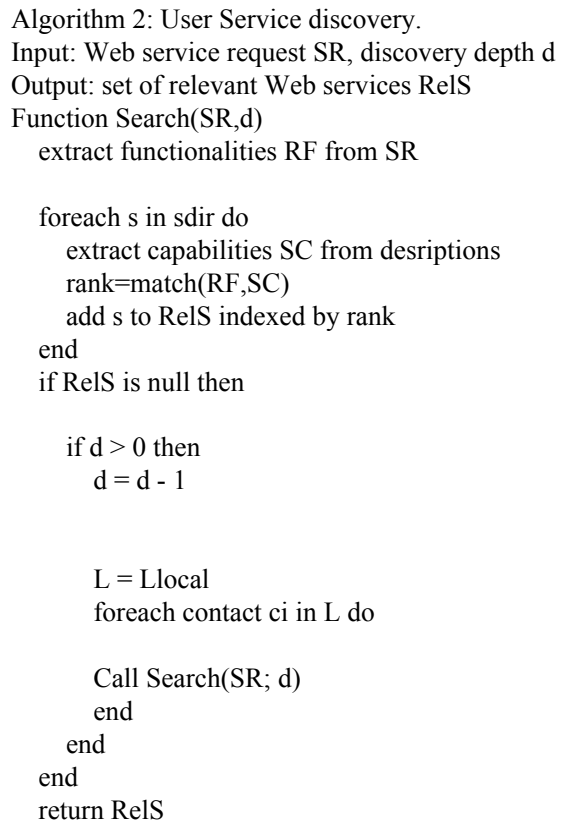

The discovery mechanism applies Algorithm 2 to find Web services relevant to a user's request by matching the required functionalities with capabilities offered by Web services. The algorithm is also distributed and recursive like the publication algorithm. It ranks the retrieved relevant services (RELS) according to the similarity between the required functionalities by a user request and the offered capabilities by a Web service.

\section{CONCLUSION AND FUTURE WORK}

In this paper, we propose an approach to apply mobile technology to portal-based E-Learning system and design a M-Learning system based on the principles of Service Governance in SOA framework. The approach to design a M-Learning makes it S.C.A.L.E. Applying Service Governance on SOA for rendering and designing different system services makes the system more usable from business aspects. Service Governance provides rules and policies on the use of services. It also provides security and privacy to M-Learning. The experience and performance results gained from the system design and implementation processes provides us with positive feedback regarding a successful and efficient system design approach for a ubiquitous system. We believe this is a trend in future development of M-Learning Systems and the system approach can be applied to the systems in other fields with similar stringent requirements. 
PAPER

AN SOA APPROACH TO VIRTUAL CLASSROOM WITH CONTENT REPURPOSING

\section{REFERENCES}

[1] Ayman Alnsour, Zahraa Muhsen, Maher Dababnah, Mohammad Ali Eljinini, Khalil Ali Barhoum. "Implementing Moodle as a Tool to develop the Isra University e-learn system", IJCSNS International Journal of Computer Science and Network Security, volume 11, pp.120-124, 2011.

[2] Yueh-Min Huang, Po-Sheng Chiu, Tzu-Chien Liu, Tzung-Shi Chen. "The design and implementation of a meaningful learningbased evaluation method for ubiquitous learning", Computers \& Education, pp. 2291-2302, 2011. http://dx.doi.org/10.1016/ j.compedu.2011.05.023

[3] Sahilu Wendeson, Wan Fatimah Wan Ahmad, Nazleeni Samiha Haron, "Platform Independent Mobile Learning Tool", International Journal of Computer Applications, volume 19, pp.32-38, 2011.

[4] Francesco Di Cerbo, Gabriella Dodero Paola Forcheri. "Ubiquitous Learning Perspectives in a Learning Management System", Interaction Design \& Architecture, volume 9, pp.37-48, 2010.

[5] Kaldoudi E, Dovrolis N, Giordano D, Dietze S. "Educational Resources as Social Objects in Semantic Social Networks", Proceedings of the Linked Learning 2011: 1st International Workshop on eLearning Approaches for the Linked Data Age, 2011.

[6] The MetaMorphosis+ social network http://metamorphosis.med.duth.gr

[7] SHANMUGAPRIYA M, Dr TAMILARASI A. "DESIGNING AN M-LEARNING APPLICATION FOR A UBIQUITOUS
LEARNING ENVIRONMENT IN THE ANDROID BASED MOBILE DEVICES USING WEB SERVICES", Indian Journal of Computer Science and Engineering, volume 2, pp.22-30, 2011.

[8] A.M. RIAD, H. A. El-GHAREEB. "A Service Oriented Architecture to Integrate Mobile Assessment in Learning Management Systems", Turkish Online Journal of Distance Education-TOJDE, volume 9, pp.200-219, 2011.

[9] Luiz Cláudio N. da Silva, Francisco M. Mendes Neto, Luiz J. Júnior, Raphael de C. Muniz. "An Agent-Based Approach for Supporting Ubiquitous Learning", International Journal of Scientific \& Engineering Research, volume 2, pp.1-8, 2011.

\section{AUTHORS}

Kong Xiangsheng is a Research Scholar in the Department of Computer Engineering, Xinxiang University, Xinxiang, China (e-mail: fallsoft@163.com). He received B.E. Degree in 2003 from Information Engineering University, China. He has teaching experience of 10 years. He has published one PHP book and two MySQL books and four international papers. His interests are in Systems Analysis \& Design and Software Testing.

Submitted 27 July 2013. Published as re-submitted by the authors 11 February 2014. 